\title{
A Comparison of Flow Rates and Pressure Profiles for N-Sequential Inlets and Three Related Seal Configurations
}

R. C. Hendricks

Lewis Research Center

Cleveland, Ohio

Prepared for the

Cryogenic Engineering Conference and International

Cryogenic Materials Conference

cosponsored by the CEC/ICMC, U.S. Dept. of Commerce, and the National Bureau of Standards

Colorado Springs, Colorado, August 15-19, 1983 
A COMPARISON OF FLOW RATES AND PRESSURE PROFILES FOR N-SEQUENTIAL

INLETS AND THREE RELATED SEAL CONFIGURATIONS

\author{
R.C. Hendricks \\ National Aeronautics and Space Administration \\ Lewis Research Center \\ Cleveland Ohio 44135
}

\title{
INTRODUCTION
}

In general, dynamic seals can be categorized into four basic types, shaft, face, labyrinth, blade tip or their combinations. The flow field for the shaft or cylindrical seal is simplest to describe and the tip seal is the most complex due to a combination of axial flow around the blade and circumferential flow over the tip.

In analyzing a seal, three fundamental characteristics are important: (i) the leak rate and associated pressure profile; (ii) the response of the flow field to eccentric positioning of the centerbody, which provides seal stiffness and dampening essential to turbomachine stability ${ }^{1}$ and; (iii) applicability of a given result to other working fluids.

Critical mass flux or leak rates were determined in Refs. 2 to 4, and pressure signatures were established for flow through simulated turbopump cylindrical, stepped cylindrical and labyrinth shaft seals. Concentric and fully eccentric (to point of rub) positions were examined. The data were taken with fluid nitrogen and hydrogen. In general it was found that the mass flux or leak rate, for each configuration could be normalized using the principles of corresponding states and the theory of two-phase-choked flows. The presssure profiles, however, did not show any direct correspondence ${ }^{5-8}$ as explained in Refs. 7 and 8. 
Many seals effectively have multiple inlets. Labyrinth seals are good examples of this. In Refs. 9 and 10, flow rate and axial pressure profile data for fluid nitrogen are presented for $20,15,10$, and $7 \mathrm{~N}$-sequential orifice-inlet configurations uniformly spaced at $15.5 \mathrm{~cm}$. These data were correlated over a wide range in reduced inlet stagnation temperature (from 0.7 to ambient) and reduced inlet stagnation pressure (up to 2) and are in general agreement with previous studies of one to four inlets. Experimental and theoretical agreement for liquid and gas flow data was acceptable but inconclusive in the near thermo-dynamic critical regions. The objective of this paper is to compare normalized leakages (flow rates) and pressure profiles for the three seal geometries of Refs. 2, 4, 7, and 11 with those of the classic venturi Refs. 5 and 6 and the $\mathrm{N}$-sequential orifice configuration to provide a relative measure of seal effectiveness Refs. 8 to 10 .

\section{SYMBOLS}

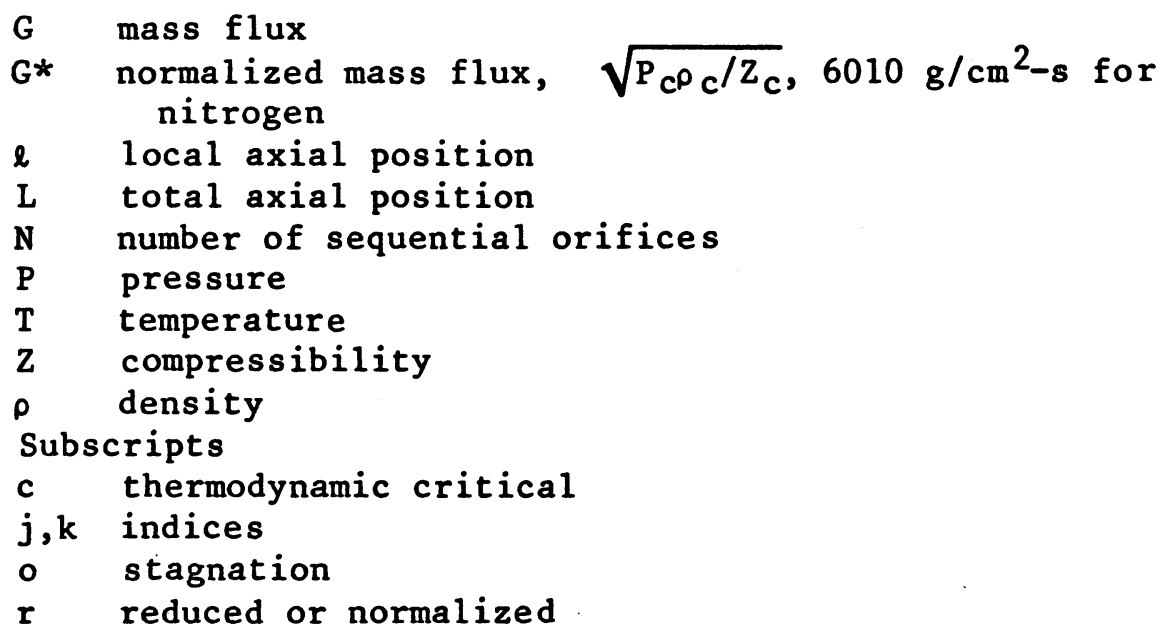

\section{GEOMETRIC CONFIGURATIONS}

Figure la shows the straight cylindrical seal where the centerbody diameter is $8.4244 \mathrm{~cm}$ and the seal length is $4.13 \mathrm{~cm}$ with a clearance of $0.0135 \mathrm{~cm}$. Figure $1 \mathrm{~b}$ shows the three step cylindrical seal. In general, the clearance is $0.0127 \mathrm{~cm}$ with a 0.038 to $0.051 \mathrm{~cm}$ slot spacing between shaft shoulder and the housing at each step and a total length of $4.62 \mathrm{~cm}$. The shaft diameters were $7.9233 \mathrm{~cm}, 7.8346 \mathrm{~cm}$, and $7.6944 \mathrm{~cm}$, respectively, decreasing in the direction of flow. Figure lc shows two of the three step labyrinth type seals with 12,11 , 10 teeth per step at nominal diameters of $8.077 \mathrm{~cm}, 7.976 \mathrm{~cm}$, and $7.874 \mathrm{~cm}$, respective$1 \mathrm{y}$, in the direction of flow with an overall length of $4.38 \mathrm{~cm}$. 
Figure 1d illustrates the $\mathrm{N}$-inlet test configurations. The orifices, $0.478 \mathrm{~cm}$ diameter with $\ell / D$ of 0.5 , were spaced at 32 orifice-diameters or approximately $15.5 \mathrm{~cm}$ aperture to aperture.

\section{RESULTS AND-DISCUSSION}

\section{Choked Flow Rate}

From the conservation equations, choked flow and normalizing parameters can be determined which can be used to correlate data for a variety of fluids.5,6 Further, the $N$-sequential orifice configuration can also be solved using a modified form of these techniques where the governing equations are solved at each orifice assuming the carryover (jet kinetic energy or fluid recovery due to incomplete expansion) to be small, and iterated to a solution.10 Although many theoretical calculations have been made to relate the flow rates in the various geometries, the methods are complex and described in Refs. 5, 6, 10 and will not be repeated herein. In all cases the mass flux, $G_{r}$ (i.e., leakage rate), data were correlated using the normalizing parameter G*

$$
G_{r}=\frac{G}{G^{\star}}
$$

as a function of reduced inlet stagnation pressure and inlet stagnation temperature:

$$
\begin{aligned}
& P_{r, 0}=\frac{P_{o}}{P_{c}} \\
& T_{r, 0}=\frac{T_{r, o}}{T_{c}}
\end{aligned}
$$

either a constant or in general a parameter. The normalizing parameters relating mass flux, $G *, P_{c}$, and $T_{c}$ are only dependent on the properties of the working fluid at the thermodynamic critical point. These corresponding states parameters have been used to correlate large sets of data for a variety of simple fluids and are applied to the nitrogen data for the seal and $\mathrm{N}$-sequential orifice configurations.

Figure $2 \mathrm{a}$ presents the reduced flow rates at $\mathrm{T}_{r, 0}=0.7$ as a function of reduced inlet stagnation presssure for the venturi, the three seal configurations and $\mathrm{N}$-sequential orifices. The values for $N=33$ were obtained by extrapolating the data and using the analytical treatment presented in Ref. 10 . On a relative basis, one can say that the cylindrical seal behaves 
much like a sharp edge orifice i.e., $0.6 \times G_{r}$, venturi $(0.5 \times$ $G_{r}$, theory). The three step seal provides approximately $1 / 3$ less leakage $\left(0.7 \times G_{r}\right.$, cylindrical) and the labyrinth seal provides about $1 / 5$ less leakage $\left(0.8 \times G_{r}, 3-s t e p\right)$. The 33 -sequential orifices seal has about $1 / 2$ the leakage of the 33-tooth labyrinth seal ( $0.5 \times \mathrm{G}_{\mathrm{r}}$, 33-tooth labyrinth), which is indicative of carryover in the seal. Further, these results for mass flux, leakage, are not significantly influenced by eccentricity.

Figure $2 b$ presents the reduced flow rates at $T_{r, o}=2.2$ (ambient gas) for the same geometries of Fig. 2a. Again on a relative basis, one can say that the cylindrical seal behaves somewhat like an orifice i.e., $0.7 \times G_{r}$, venturi. The three step seal provides approximately $1 / 3$ less leakage $\left(0.7 \times G_{r}\right.$, cylindrical) and the labyrinth seal provides about $1 / 3$ less leakage $\left(0.7 \times G_{r}, 3-s t e p\right)$. The 33-sequential orifices has about $1 / 2$ the leakage of the 33-tooth labyrinth seal $\left(0.5 \times G_{r}\right.$, 33-tooth labyrinth), again indicating the influence of carryover in the seal. These results do not appear to be significantly influenced by eccentricity or small convergent taper.11

\section{Pressure Profiles}

In Fig. 3, the axial pressure profiles are normalized in terms of the inlet stagnation pressure and plotted as a function of normalized length $(l / L)$. The normalized length for $\mathrm{N}$-squential inlets can be expressed as the number of orifices up to 1 (i.e., $\Sigma N_{j}$ ) to the length to choke L (i.e., $\Sigma N_{k}$ ), where $k \geq j .10$

In Fig. 3a, the normalized pressure profiles for the seal geometries and $\mathrm{N}$-sequential inlets are linear with normalized length for $T_{r, 0}=0.7$. This is significant because the geometries are very different yet when properly normalized they appear similar. These profiles indicate a universality between geometries for a designer knowing the inlet stagnation and choke condition, the pressure profile is then known. The pressure profiles are very important to turbomachine stability because there are usually several sealing surfaces between bearing supports.1

\section{SUMMARY}

Studies of experimental and analytic results have been carried out to determine the effectiveness of labyrinth, 3-step, and cylindrical type shaft seal configurations. Similar studies have also been carried out for $\mathrm{N}$-sequential orifice type inlets. 
The flow rates and pressure profiles were calculated based on a two-phase choked flow approach and modified for the labyrinth seal and sequential inlet geometries. For the $\mathrm{N}$-sequential inlet configuration, the carryover (jet kinetic energy not dissipated during expansion) was assumed to be small and the solution required an iterative procedure. All data were normalized in terms of the parameters, $G *, P_{c}$, and $T_{c}$ which depend only on fluid properties at the thermodynamic critical point.

The flow rates, or seal leakages, are significantly influenced by the geometric configuration and fluid state. On the average, the cylindrical seal leakage is about 60 percent that of a venturi; the 3 -step is about 70 percent of the cylindrical seal; the 33-tooth labyrinth is about $75-80$ percent of the 3-step seal; and the 33-sequential orifice inlet configuration is about 50 percent of the 33-tooth seal. The implication for the latter two geometries is that carryover can represent a significant part of the leakage.

The normalized pressure profiles are less distinctive, but most important to seal dynamics. In general these profiles are linear for liquid flows with little effect due to geometry. However separation effects observed in the 3-step seal are nonlinear and could profoundly alter turbomachine dynamics. Such a profile is common to eccentric placement of the shaft-housing configuration (i.e., to the point of rubbing). The normalized pressure profiles gaseous operation are parabolic and are more sensitive to geometric changes. Such normalized profiles suggest universality and are readily adapted to design methodology. More work will be required to establish these concepts.

\section{REFERENCES}

1. Rotordynamic Instability Problems in High-Performance Turbomachinery. Proceedings of a workshop at Texas A\&M University, College Station, Texas, May 12-14, 1980, NASA CP 2133.

2. R. C. Hendricks, Investigation of a Straight Cylindrical Seal for High Performance Turbomachines, NASA TP-1850, (1981).

3. R. C. Hendricks, Investigation of a Three Step Cylindrical Seal for High Performance Turbomachines, NASA TP-1849, (1981).

4. R. C. Hendricks, Investigation of a Three Step Labyrinth Seal for High Performance Turbomachines, NASA TP-1850, (1981).

5. R. C. Hendricks, J. V. Sengers and R. J. Simoneau, : Toward the Use of Similarity Two-Phase Choked Flows. ASME HTD-14 Scaling in two-phase choked flows. ASME Winter Annual Meeting, Chicago IL, (1980). 
6. R. J. Simoneau, R. C. Hendricks, Two phase choked flow of cryogenic fluids in converging diverging nozzles. NASA TP 1484 (1979).

7. R. C. Hendricks, A Comparative Evaluation of Three Shaft Seals Proposed for High Performance Turbomachinery. Presentation at the ASLE/ASME Joint Lubrication Conf. Washington DC, Oct 5-7, 1982.

8. R. C. Hendricks, T. T. Stetz, Flow through sharp edge inlets, aligned sequential apertures of the orifice and Borda types, and comparisons to three high performance turbomachine seals. Presentation ASLE Annual Meeting, Pittsburgh PA, 1981.

9. R. C. Hendricks, T. T. Stetz, Experiments on flow through one to four inlets of the orifice and Borda types. 1981CEC/ICMC - Cryogenic Engineering Conference, San Diego, CA, Aug. 10-14, 1981 .

10. R. C. Hendricks, Studies of flows through $\mathrm{N}$-sequential Orifices. ASME Spring Meeting Texas.

11. R. C. Hendricks, Some Flow Characteristics of Conventional and Tapered High Pressure Drop Simulated Seals, ASLE Trans. V. 24, 1, 23-28 (ASME/ASLE Lubrication Conference, Dayton OH, Oct. 1979). 


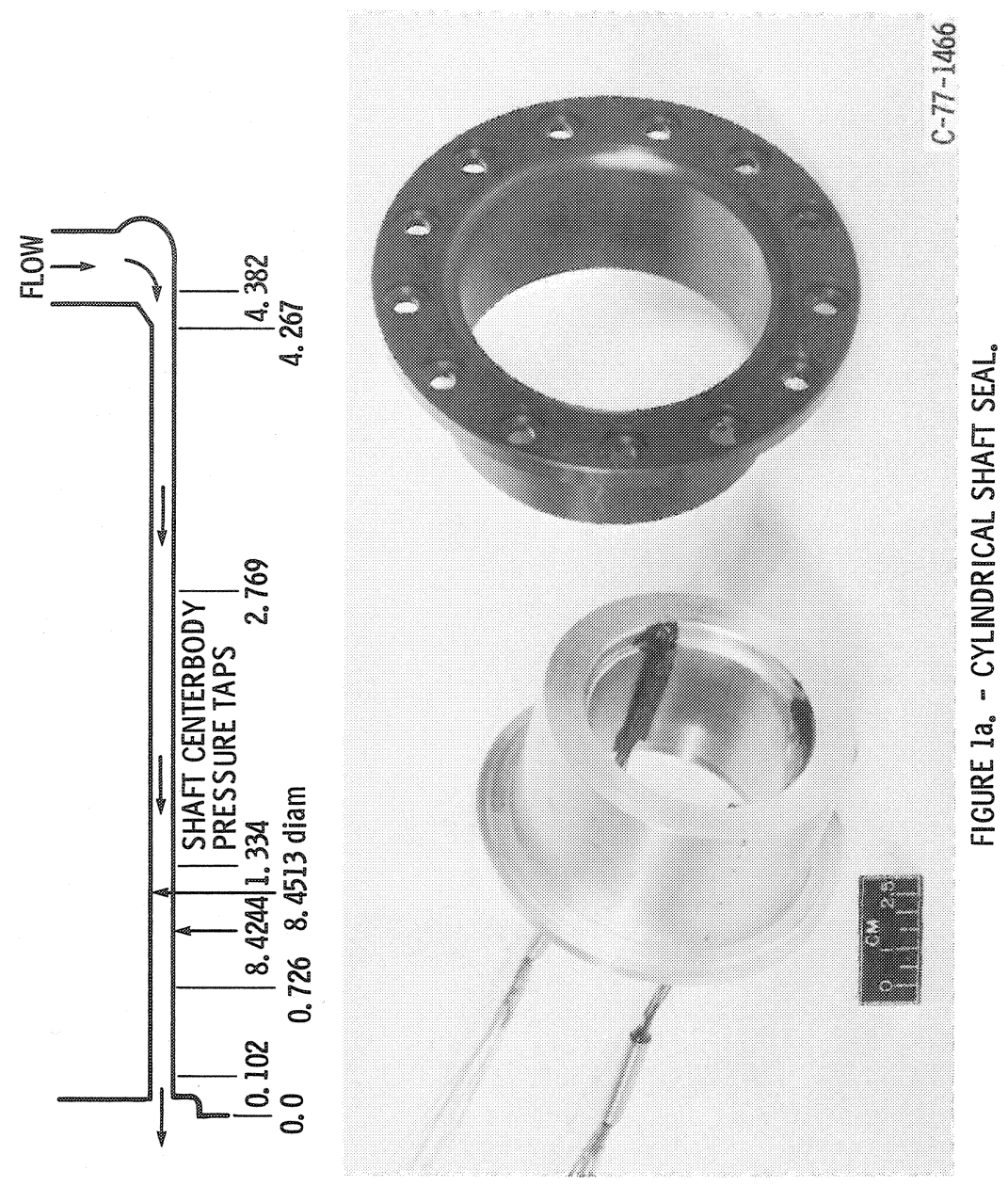




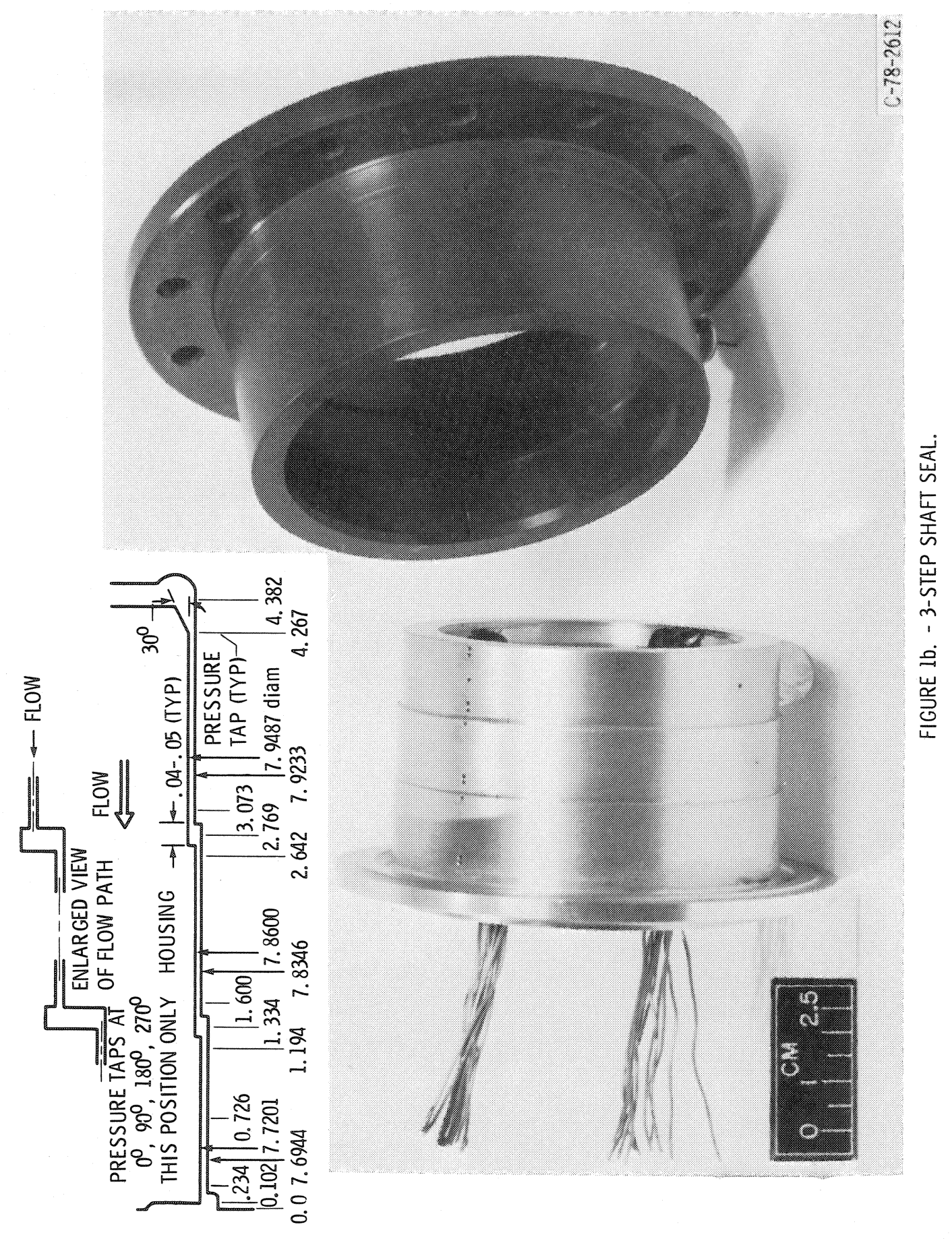




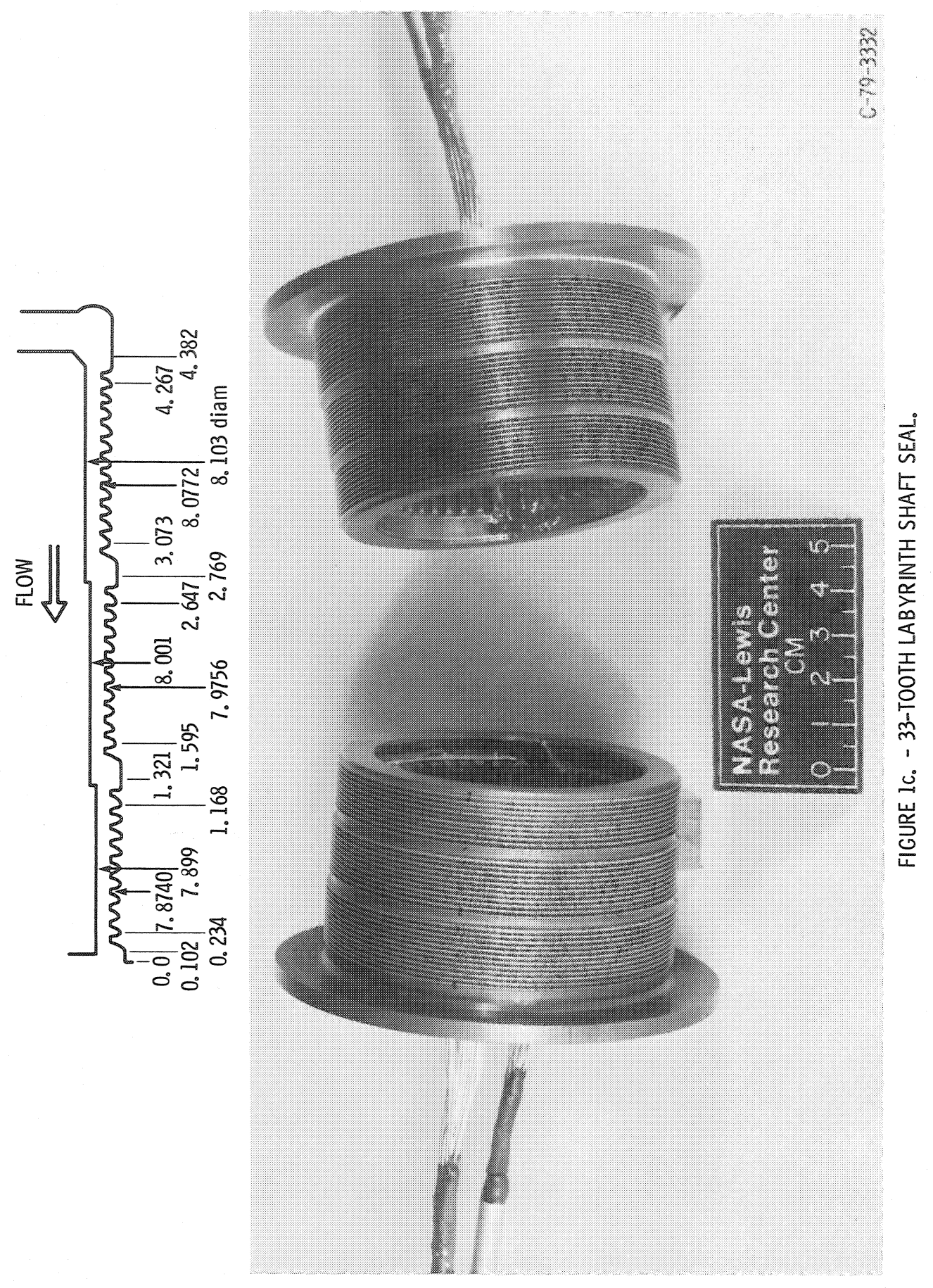




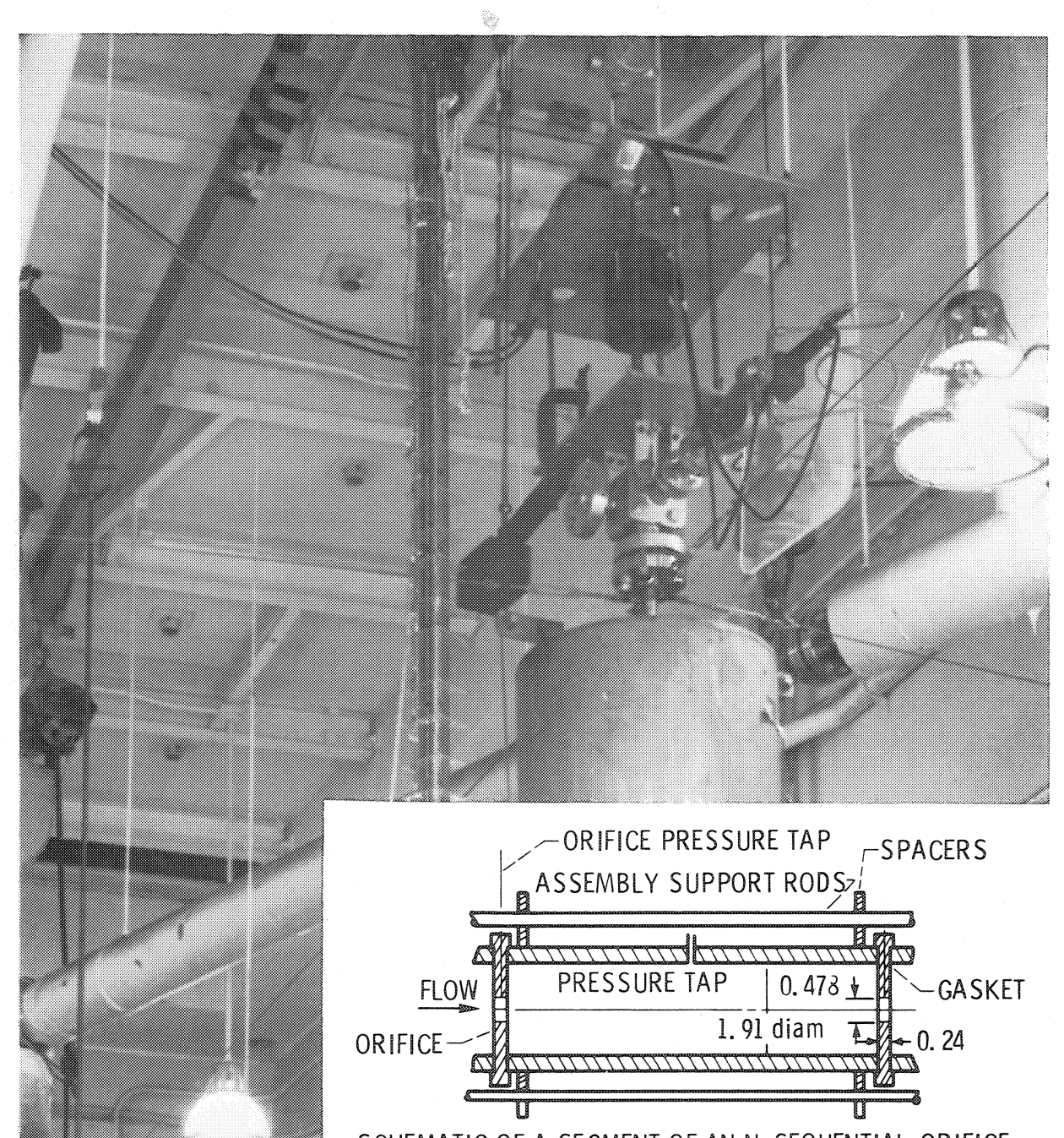

SCHEMATIC OF A SEGMENT OF AN N-SEQUENTIAL-ORIFICEINLET CONFIGURATION.

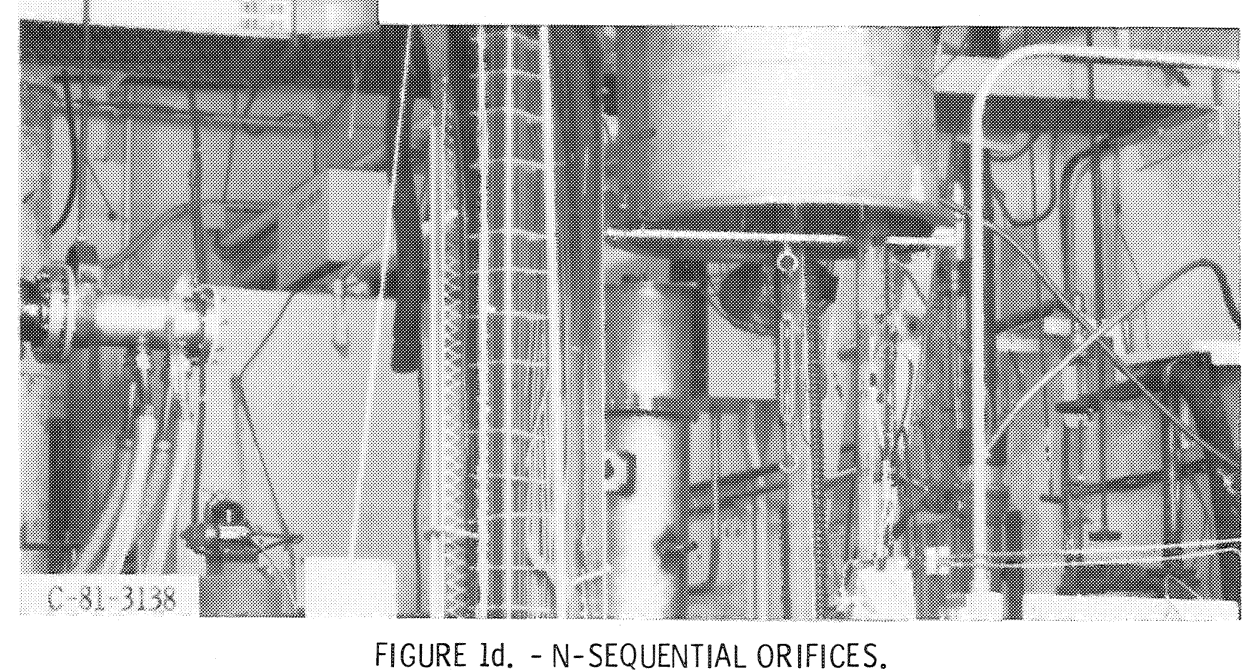




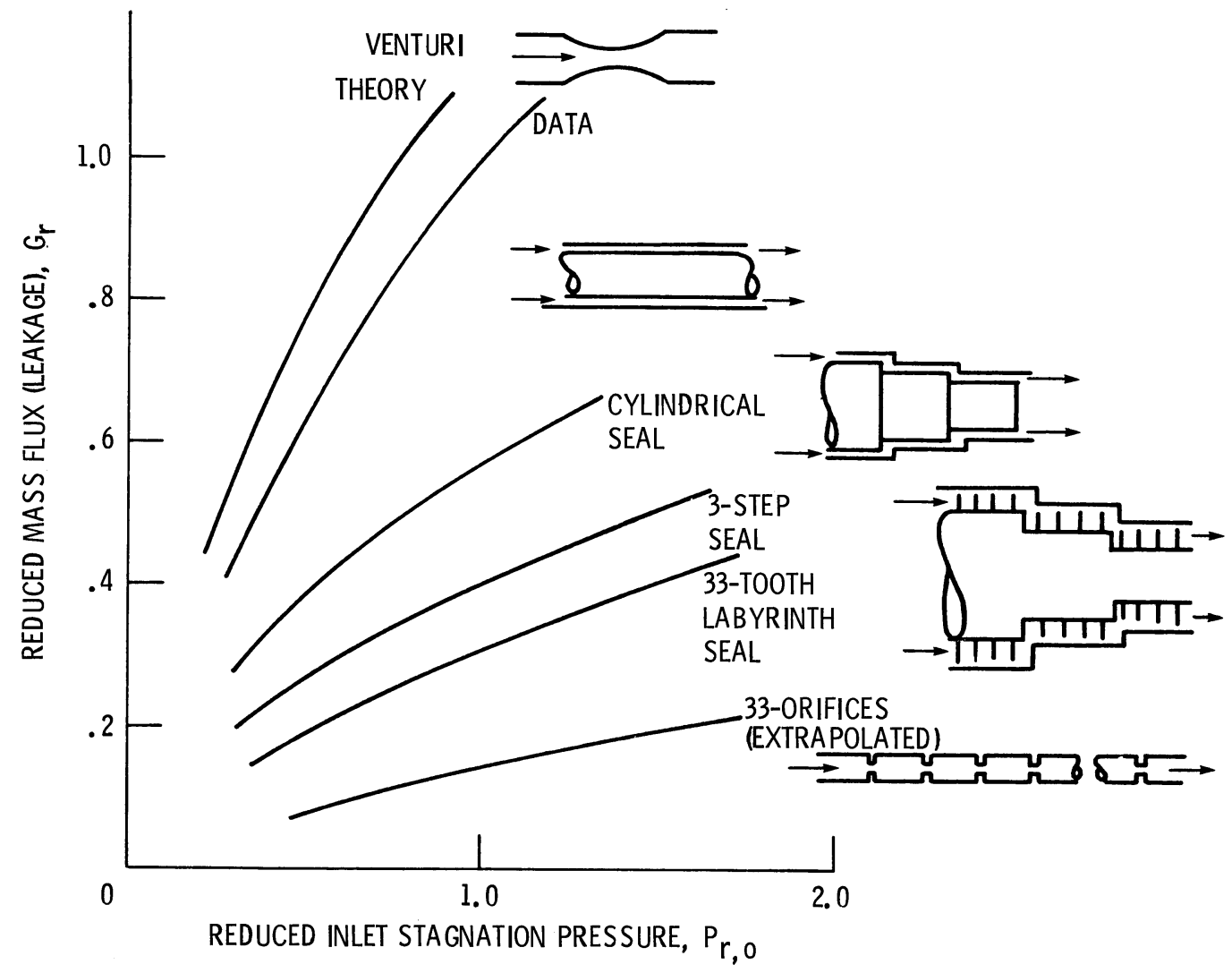

FIGURE 2a. - REDUCED MASS FLUX (LEAKAGE RATES) AS A FUNCTION OF REDUCED INLET STAGNATION PRESSURE WITH REDUCED INLET STAGNATION TEMPERATURE OF 0.7 FOR FIVE GEOMETRIC CONFIGURATIONS; VEINTURI, CYLINDRICAL SEAL, 3-STEP, 33-TOOTH LAYBYRINTH, AND N-SEQUENTIAL ORIFICES. 


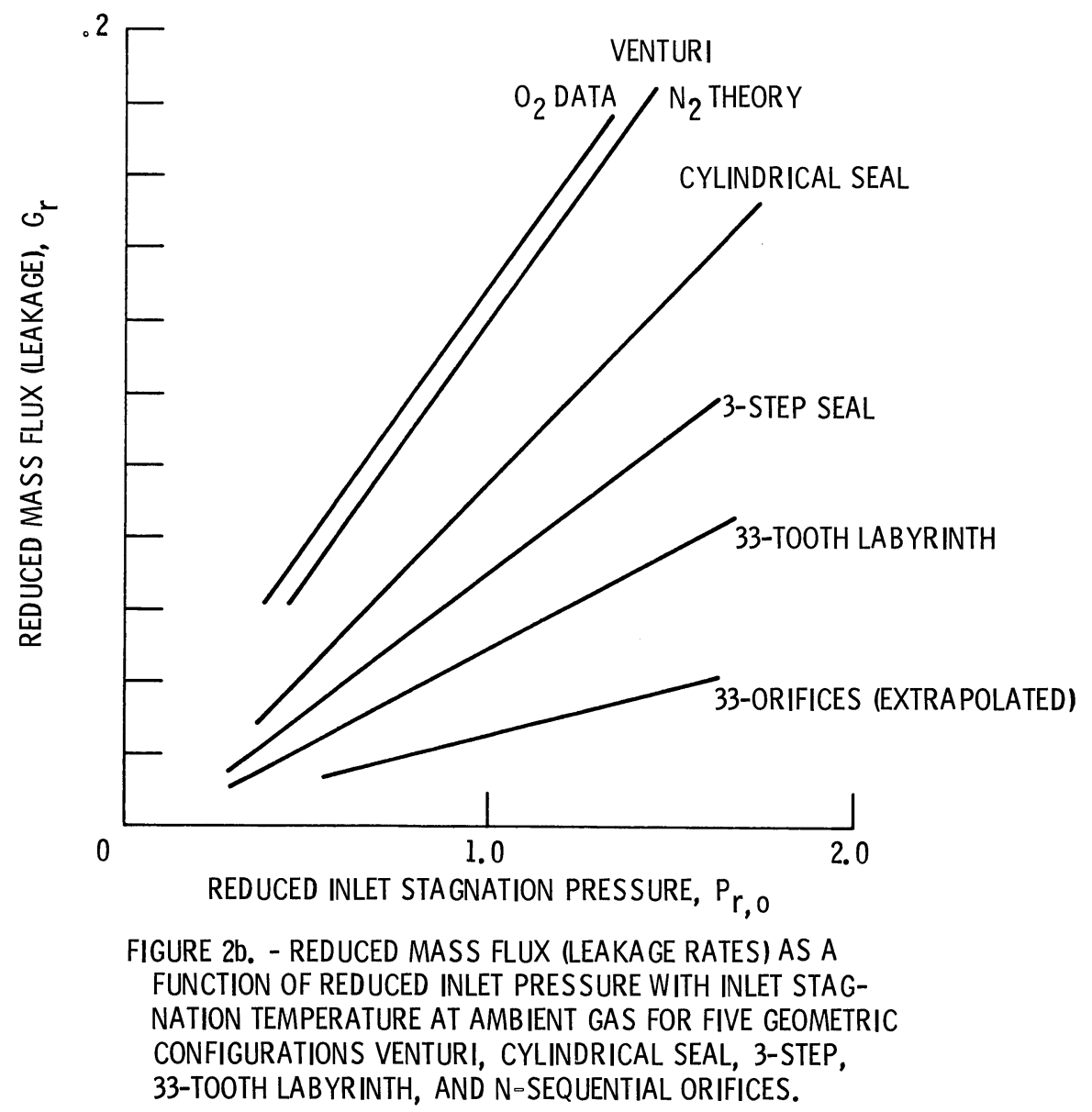



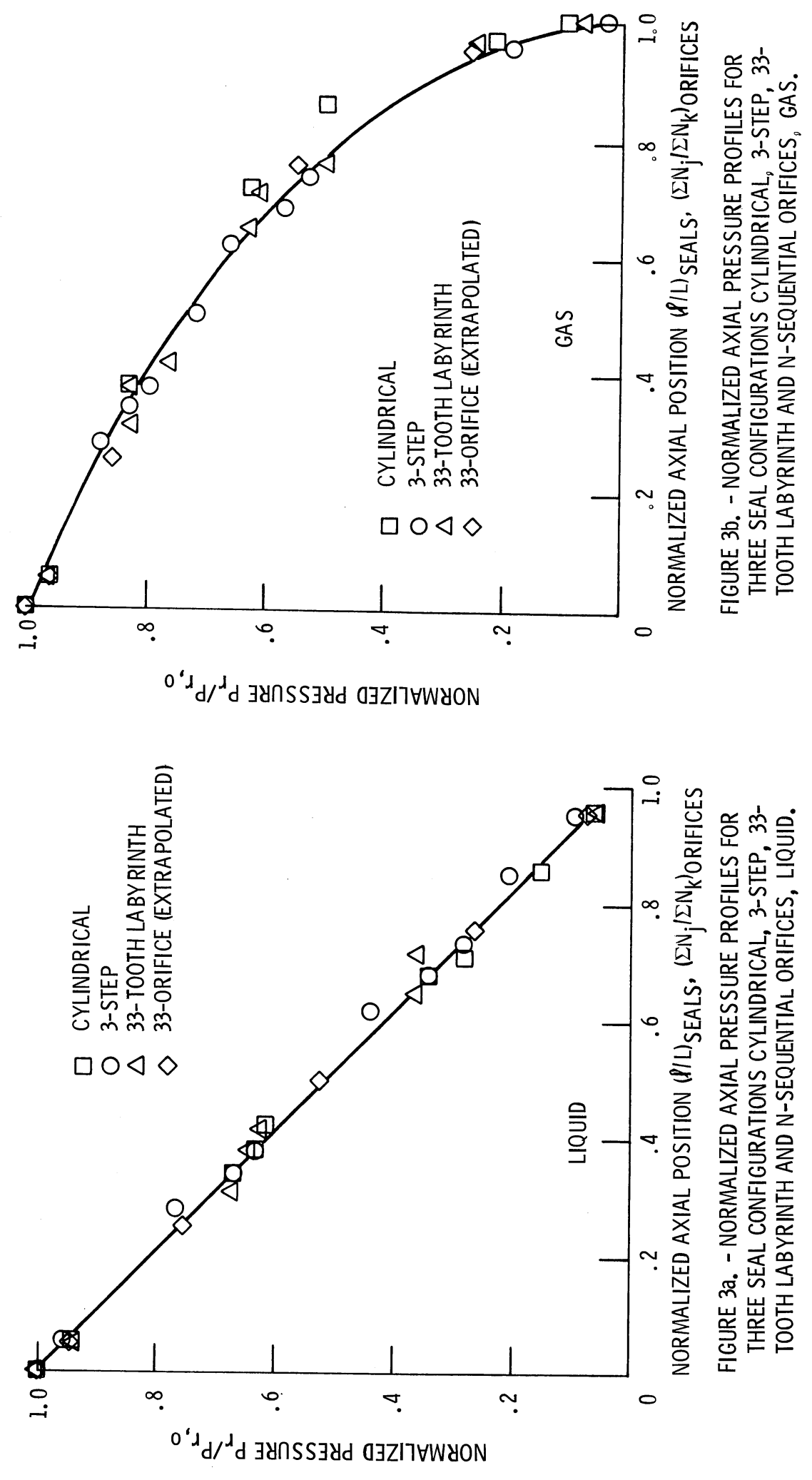


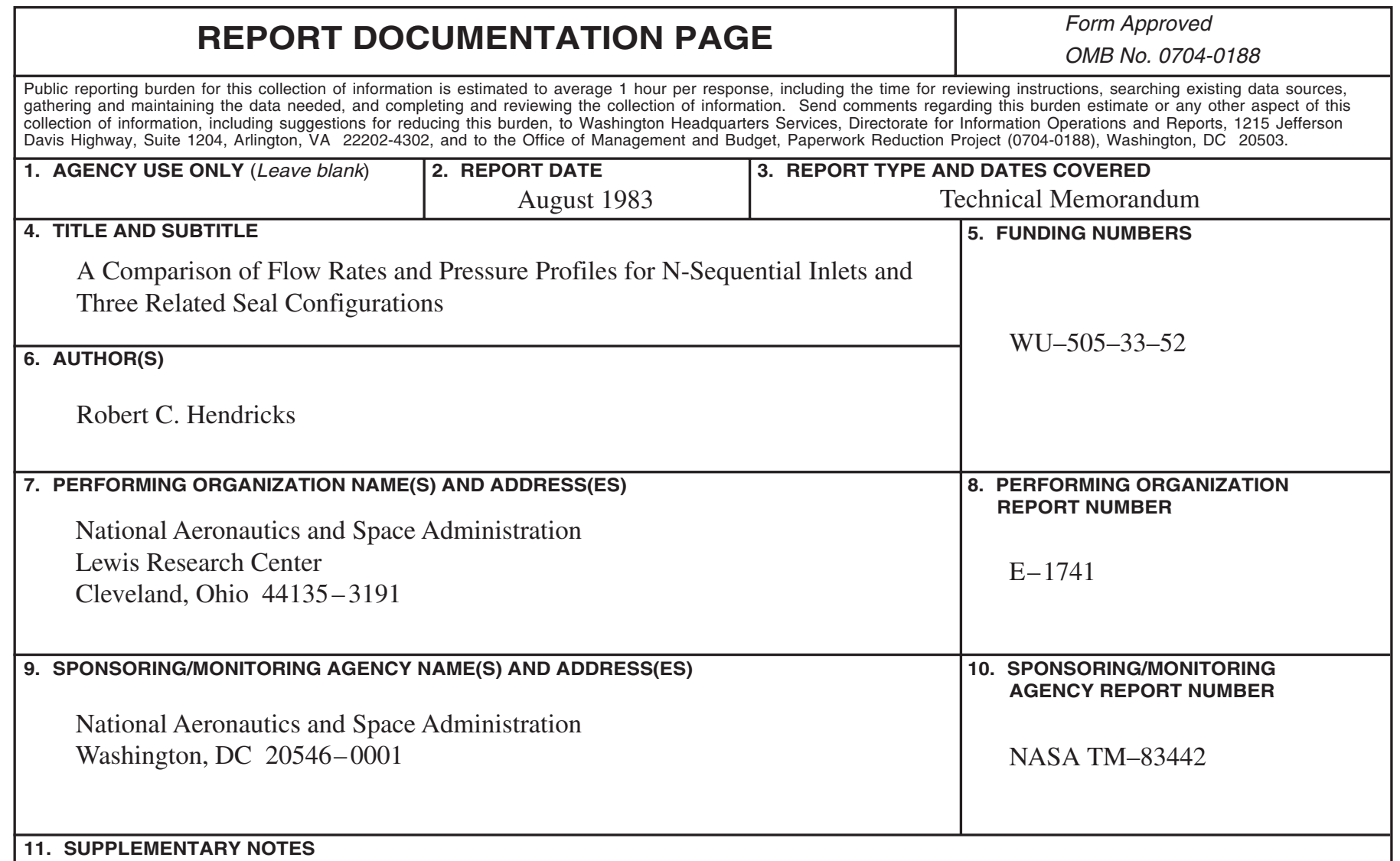

Prepared for the Cryogenic Engineering Conference and International Cryogenic Materials Conference cosponsored by the CEC/ICMC, the U.S. Department of Commerce, and the National Bureau of Standards, Colorado Springs, Colorado, August 15-19, 1983. Responsible person, Robert C. Hendricks, organization code R, 216-977-7507.

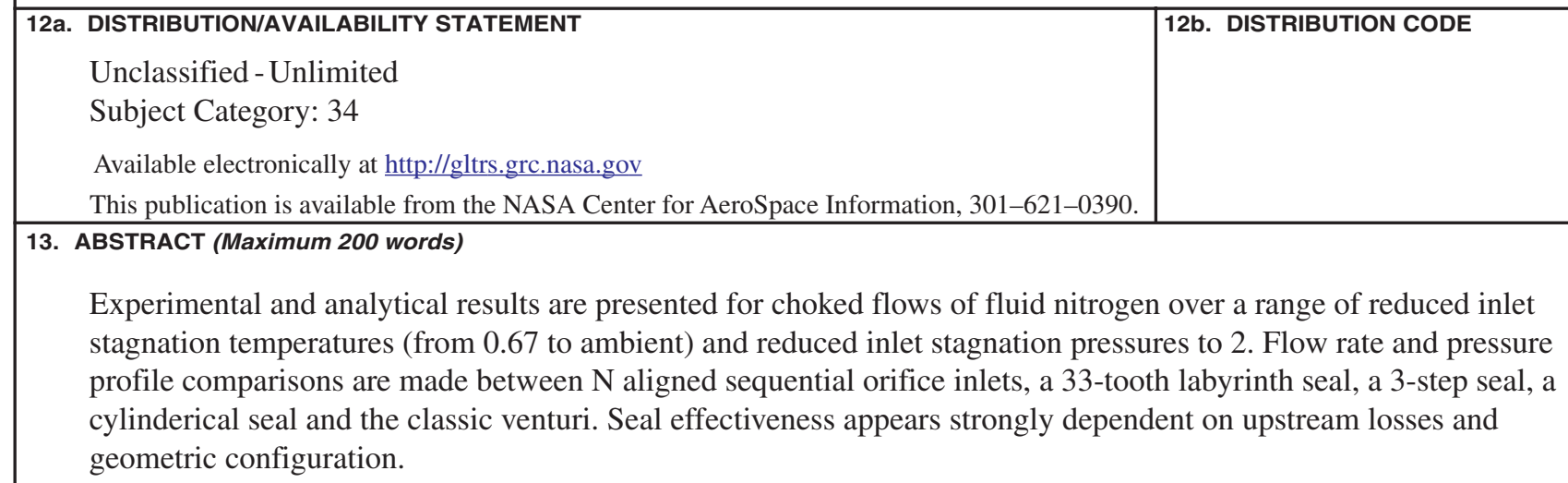

\begin{tabular}{|c|c|c|c|}
\hline \multicolumn{3}{|l|}{ 14. SUBJECT TERMS } & $\begin{array}{l}\text { 15. NUMBER OF PAGES } \\
15\end{array}$ \\
\hline \multicolumn{3}{|c|}{ Seals; Inlets; Flow rates; Pressure profiles; Sequential inlets } & 16. PRICE CODE \\
\hline $\begin{array}{l}\text { 17. SECURITY CLASSIFICATION } \\
\text { OF REPORT } \\
\text { Unclassified }\end{array}$ & $\begin{array}{l}\text { 18. SECURITY CLASSIFICATION } \\
\text { OF THIS PAGE } \\
\text { Unclassified }\end{array}$ & $\begin{array}{l}\text { 19. SECURITY CLASSIFICATION } \\
\text { OF ABSTRACT } \\
\text { Unclassified }\end{array}$ & 20. LIMITATION OF ABSTRACT \\
\hline ISN 7540-01-280-5500 & & & $\begin{array}{l}\text { andard Form } 298 \text { (Rev. 2-89) } \\
\text { scribed by ANSI Std. Z39-18 } \\
3-102\end{array}$ \\
\hline
\end{tabular}

